\title{
The Effect of High Intensity Interval Training and Herb Supplement on Heart IGF-1 Concentration in Male Rat
}

\author{
Mohammad-Ali Pirani ${ }^{1}$, Maghsoud Peeri ${ }^{{ }^{*}}$, Mohammad-Ali Azarbayjani ${ }^{1}$ \\ ${ }^{1}$ Department of Exercise Physiology, Islamic Azad University, Central Tehran Branch, Tehran, Iran
}

\author{
*Correspondence to \\ Maghsoud Peeri, \\ Tel: +982188074905 \\ Email: m.peeri@iauctb.ac.ir
}

Received November 11, 2017 Accepted January 31, 2018 Published online March 31, 2018

\begin{abstract}
Introduction: The objective of the present study was to determine the effect of 10 weeks of high-intensity interval training (HIIT) and flaxseed oil supplement on heart IGF-1 concentration in male rats.

Methods: Twenty adult male Wistar rats were randomly divided into saline, saline-training, supplementation, and supplementation-training groups. The training groups performed training ( 10 weeks, 5 sessions per week, 90\%-95\% VO2 max) on a rodent treadmill. The supplementation groups received flaxseed oil supplement $(300 \mathrm{mg} / \mathrm{kg})$. The rats were sacrificed 5 days after the last training session. The heart tissue was collected, and insulin-like growth factor-1 (IGF-1) was measured in the heart tissue.

Results: Training increased the concentration of the heart IGF-1 $(P=0.01)$. The concentration of heart IGF-1 was higher in the flaxseed oil-supplemented group than the saline-treated groups. $(P=0.003)$. The interaction between training and supplementation also led to an increase in heart IGF-1 concentration ( $P=0.001)$.

Conclusion: The increase of heart IGF-1 in trained supplemented group suggests that training and flaxseed oil can help to improve cardiac function.

Keywords: Flaxseed oil, Insulin-like growth factor-1, Heart, exercise
\end{abstract}

\begin{abstract}
Introduction
Cardiovascular diseases, which take the lives of thousands of people every year, are one of the important concerns in societies. ${ }^{1}$ The heart is a striated muscle and studies have shown that in response to stimuli, this muscle can make itself more consistent or repair itself, just like other muscles of the body. ${ }^{2}$ Mobility and immobility are some of the stimuli that are effective on the heart which can alleviate a heart disease by hypertrophy or cause a heart disease by atrophy respectively. ${ }^{3-7}$
\end{abstract}

IGF-1 (insulin-like growth factor-1) is a key factor for adjusting myocardial growth. ${ }^{8}$ Physical activities are factors that affect IGF-1 levels. Previous studies have shown that depending on the training type, heart tissue responds differently. Resistive activities lead to increased thickness of the heart septa, whereas endurance activities increase the volume of the heart cavity. ${ }^{9}$
Therefore, it seems that the type of the training is influential on IGF-1.

In recent years special attention has been paid to high-intensity interval training (HIIT) due to its beneficial effects on health status. The effects of a long-term organized period of HIIT training on the cardiac IGF-1 levels are unclear. Recent studies have revealed that natural materials can influence the amount of generated peptides and proteins. Flaxseed has been used as a drug in traditional Mediterranean medicine. The oil extracted from this seed contains the major components and benefits of flax seeds. This plant contains many micronutrients such as edible fiber, manganese, vitamin B1 and alpha-linolenic acid (Omega 3), which seem to be related to cardiac and muscular performance..$^{10,11}$

The effects that consuming flaxseed for a single period has on IGF-1 concentration are not clear. Further, besides independent

(C) 2018 The Author(s); Published by Zabol University of Medical Sciences. This is an open-access article distributed under the terms of the Creative Commons Attribution License (http://creativecommons.org/licenses/by/4.0), which permits unrestricted use, distribution, and reproduction in any medium, provided the original work is properly cited. 
effects of physical activity and flax seed, their interactional effect is not well clear. Therefore, the present investigation aims to determine the effects of one period of HIIT and supplementary flax seed oil on the concentration of IGF-1 in the cardiac tissue of male rats.

\section{Methods}

\section{Animals}

The present study was conducted according to laboratory animal care principals and all moral principles regarding working with laboratory animals according to the Helsinki Protocol (1985). In the current research, 20 male Wistar rats, acquired from Pastor Institute of Karaj, were selected randomly. The animals were preserved in a special animals' home for rodents with a temperature of $22^{\circ} \mathrm{C}( \pm 2), 45 \%-50 \%$ moisture and a darkness-lightness cycle (12 hours of light and 12 hours of dark), kept in special cages made of compact plastic with metal lids whose bottom was covered with clean wood chips. To feed the animals, we used special compact food for laboratory rats, manufactured by Behparvar Company (Karaj), and refined water in $500 \mathrm{ml}$ bottles served freely. ${ }^{12}$ To perform the training plan, rats were classified into 4 groups (5 rats in each one) including saline (CS), training-saline (T-S), supplementary of flax seed (CO) and trainingsupplementary of flax seed (TO).

\section{Flaxseed Oil and the Way They Were Provided}

Fresh flax seeds were gathered from regions in Mehriz (Yazd province) where they grow, and their oil was extracted using oil press machine. ${ }^{13}$ The extracted oil was fed orally to the relevant groups based on rats' weight before each training session (300 $\mathrm{mg} / \mathrm{kg}$ dosage). Saline was fed to control groups.

\section{Period and Timing of Training}

Familiarizing rats with the intense periodic sports protocol was done during 10 training sessions, in such a way that during the first day of training, the rats were placed on the treadmill with utmost care and peace, and started training with a low and uniform speed. In the next sessions, after rats had moved forward well and space with the plan, in order to get familiarized with the periodic protocol of interest with low speeds, periodic training was applied. During 2 weeks of training, the time and intensity increased as rats achieved the duration of training of 18 minutes at the end of 2 weeks. After 2 weeks, without any problems with the protocol or rats getting familiar, the rats started the main training for 10 weeks. One must note that treadmill slope was 0 during all training stages, and that familiarization was performed for non-training groups as well. At the end of 2 weeks of familiarization, maximum consumed oxygen by rats was measured and rats started the training based on the training protocol allocated according to the percent of maximum consumed oxygen (which was transformed to meters per minute). At the end of both weeks, maximum consumed oxygen test was estimated and a new training speed was applied for the next week.

Each session of performing HIIT included 30 minutes of sports activity (Table 1). The training program included 3 high-intensity and low-intensity periodicities. High-intensity periodicities with $90 \%-100 \%$ maximum consumed oxygen were performed for 4 minutes and low-intensity periodicities with 50\%-60\% maximum consumed oxygen were performed for 2 minutes. It must be noted that 6 minutes with 50\%-60\% intensity of maximum consumed oxygen was considered for cooling and heating segments. ${ }^{13,14}$ Meanwhile, the control group for balancing the effect of stress was put on the treadmill for 15 minutes without any movement. Training protocol continued until 5 days prior to sacrificing the rats.

\section{Determination of VO2 Max}

Since we did not have access to direct devices such as a decomposition device and respiratory gas analyzer and based on recent research conducted by Hoydal et $\mathrm{al}^{15}$ an indirect protocol was employed as follows: first, warming up was done for 10 minutes with low speed (10 $\mathrm{m} / \mathrm{min}$ ). After this, the trials started with rats running with a velocity of $15 \mathrm{~m} / \mathrm{min}$ for 2 minutes, and then the speed of the rolling ribbon was increased by $0.03 \mathrm{~m} / \mathrm{s}$ $(1.8-2 \mathrm{~m} / \mathrm{min})$ every 2 minutes until the animals could not run anymore. This speed was considered as $100 \%$ the maximum consumed oxygen, and the least maximum consumed oxygen was calculated as a percentage of this intensity.

\section{Measuring IGF-1 Concentration}

The cardiac tissue sample was placed in special tubes after rinsing in saline and then poured into liquid nitrogen. Tissue IGF-1 concentration was measured using the ELISA method (Yekta Tajhiz Azma, Cat No: YT9065) according to guidelines of the manufacturer.

Table 1. Design of High-Intensity Periodic Training Protocol

\begin{tabular}{llcc}
\hline \multirow{2}{*}{ Training Stages } & Warm up & \multicolumn{2}{c}{ The Main Body of Training (3 Periods) } \\
\cline { 3 - 4 } & & Low-Intensity Periodicity & High-Intensity Periodicity \\
\hline Training duration $(\min )$ & 6 & 2 & 4 \\
Training intensity $\left(\mathrm{VO}_{2}\right.$ max) & $50 \%-60 \%$ & $50 \%-60 \%$ & $90 \%-100 \%$ \\
\hline Protol down & $50-60 \%$ \\
\hline
\end{tabular}

Protocol-based on Rahmati-Ahmadabad et al and Shafiee et al. ${ }^{13,14}$ 


\section{Statistical Analysis}

The Kolmogorov-Smirnoff test was used to identify the normal distribution of data. To determine the main effect of training, supplementation, and interaction of training and supplementary, two-tailed analysis of variance (ANOVA) test was employed. The analysis was done using SPSS version 19. The significance level was considered as $<0.05$.

\section{Results}

Two-way ANOVA on cardiac IGF-1 showed a significant difference between training group and control group $(\mathrm{F}=8.502, P=0.01)$. Training led to a significant increase in IGF-1 concentration in the cardiac tissue. Further, IGF-1 concentration in supplementation groups was significantly higher compared to saline $(\mathrm{F}=15.921$, $P=0.001)$. Furthermore, IGF-1 levels showed a significant increase in training + supplementation group compared to the other groups $(\mathrm{F}=11.747, P=0.003)$ (Figure 1$)$.

\section{Discussion}

Regular physical activity has a positive effect on most organs. These organs include cardiovascular, respiratory, and neuroendocrine systems and especially the musculoskeletal system. Physical activities are a strong stimulus for generating intracellular and extracellular signals. These signals lead to the best performance efficiency of muscular fibers, homeostasis maintenance, mitochondrial biogenesis, and muscular growth and migration. ${ }^{16,17}$ Insulin-like growth factors play an important role in activating satellite cells, increasing protein synthesis, decreasing protein degradation, and hypertrophy of muscular fibers during the period of muscular growth and development. ${ }^{18}$

Research shows speed sports ${ }^{19}$ and aerobic sports activities with medium intensity ${ }^{20}$ do not cause a change in IGF-1. The findings of studies investigating the response of IGF-1 to chronic training also confirmed that both the intensity and the duration of the training determine the final levels. ${ }^{21}$ Many studies have shown that intense physical activities affect the IGF-1/IGF BP axis. Copeland and Heggie ${ }^{22}$ demonstrated increased IGF1 concentration in response to intense aerobic training. Turgut et $\mathrm{al}^{23}$ showed increased urine IGF-1 in response to a 2-hour volleyball game. Dall et $\mathrm{al}^{24}$ exhibited increased IGF-1 concentration following maximum canoeing test. Manetta et $\mathrm{al}^{25}$ showed increased IGF-1 levels following 4 months of bicycling training. Based on the results of prior research and the current one, it seems like the type of the training affects IGF-1 concentration, and that HIIT training increases IGF-1 like any other high-intensity models.

In recent decades, scientists are paying attention to the effect of natural materials, especially edible fats on receptors, proteins, and gene expression. ${ }^{13,26-28}$ Fatty acids play a role in many cellular processes such as cellular

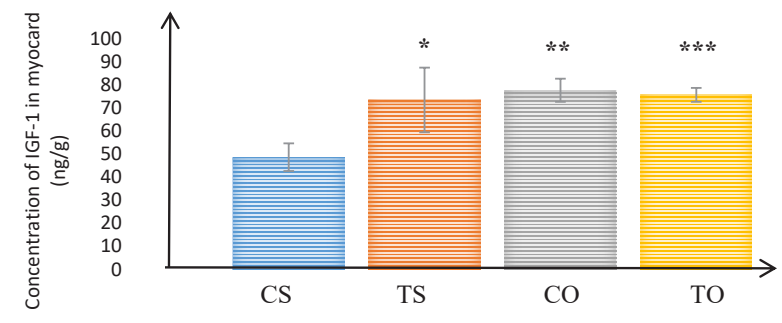

Figure 1. IGF-1 Concentration (ng/g) in the Cardiac Tissue of Male Rats in the Studied Groups. Data are reported based on the mean and standard deviation. Abbreviations: CS: control-saline supplemented, TS: training-saline supplemented, CO: control-flax seed oil supplemented, and TO: training- flax seed oil supplemented. Comparisons to controlsaline: ${ }^{*} P=0.01, * * P=0.001$, and ${ }^{* * *} P=0.003$.

apoptosis and reproduction. The flax plant abounds with unsaturated fatty acids including Omega-3 and Omega-6. Some studies have investigated the effect of fatty regimes on IGF-1. One study investigated the effect of consuming fatty food regime on the IGF system and concluded that the type and amount of fatty acid affect IGF-1 and its receptors. ${ }^{29}$ Another study indicated that fatty acids can change IGF-BP release and activate IGF-1R. ${ }^{28}$ Another study investigated the influence of Omega- 3 and Omega- 6 fatty acids on IGF-1 signaling pathway. This study revealed that both Omega-3 and Omega- 6 lead to increased IGF-IR and IGF-1 gene expression. They also showed that these fatty acids also activate protein Akt. ${ }^{30}$ Another study also revealed that unsaturated fatty acids activate Akt in the vascular endothelial cells decreasing apoptosis rate. ${ }^{28}$ Furthermore, one study showed that these fatty acids lead to increased Erk protein on IGF1 pathway. ${ }^{31}$ Therefore, it is possible that the increase of these proteins (Erk and Akt) in the gene expression pathway in response to consuming fatty acids Omega-3 and Omega-6, acts as a mechanism for increasing IGF1 levels. Anyway, in this study, these proteins were not measured and further studies are required to investigate how unsaturated fatty acids affect these pathways and IGF-1 generation.

\section{Conclusion}

In general, it seems that the training type is effective in IGF-1 concentration. The results of studies indicate that intense training affects IGF-1 concentration and the results of the current research showed that HIIT, just like any other intense training models, leads to an increase in IGF-1 concentration. Flaxseed oil constitutes unsaturated fatty acids of Omega-3 and Omega-6. These fatty acids are effective in gene expression on IGF-1 pathway components, and IGF-1 is increased in response to flax seed oil probably by these mechanisms, albeit it requires further studies.

\section{Ethical Approval}

The present study was conducted according to laboratory 
animal care principals and all moral principles regarding working with laboratory animals according to the Helsinki Protocol (1985).

\section{Competing Interests}

The authors declare that they have no competing interest.

\section{Acknowledgments}

Thereby, Ph.D. students of Department of Exercise Physiology, Islamic Azad University, Central Tehran Branch are sincerely acknowledged by the authors of this article for his helpful comments and guidance.

\section{References}

1. Hopper CA, Gruber MB, Munoz KD, Macconnie SE, Pfingston YM, Nguyen K. Relationship of Blood Cholesterol to Body Composition, Physical Fitness, and Dietary Intake Measures in Third-Grade Children and Their Parents. Res Q Exerc Sport. 2001;72(2):182-188. doi:10.1080/02701367 .2001 .10608948

2. Potthoff MJ, Olson EN, Bassel-Duby R. Skeletal muscle remodeling. Curr Opin Rheumatol. 2007;19(6):542-549. doi:10.1097/BOR.0b013e3282efb761

3. Davidsen PK, Gallagher IJ, Hartman JW, et al. High responders to resistance exercise training demonstrate differential regulation of skeletal muscle microRNA expression. J Appl Physiol (1985). 2011;110(2):309-317. doi:10.1152/japplphysiol.00901.2010

4. Czubryt MP, Olson EN. Balancing contractility and energy production: the role of myocyte enhancer factor 2 (MEF2) in cardiac hypertrophy. Recent Prog Horm Res. 2004;59:105-124.

5. Dickinson JM, Drummond MJ, Coben JR, Volpi E, Rasmussen BB. Aging differentially affects human skeletal muscle amino acid transporter expression when essential amino acids are ingested after exercise. Clin Nutr. 2013;32(2):273-280. doi:10.1016/j.clnu.2012.07.009

6. Drummond MJ, McCarthy JJ, Fry CS, Esser KA, Rasmussen BB. Aging differentially affects human skeletal muscle microRNA expression at rest and after an anabolic stimulus of resistance exercise and essential amino acids. Am J Physiol Endocrinol Metab. 2008;295(6):E1333-1340. doi:10.1152/ajpendo.90562.2008

7. Han M, Toli J, Abdellatif M. MicroRNAs in the cardiovascular system. Curr Opin Cardiol. 2011;26(3):181189. doi:10.1097/HCO.0b013e328345983d

8. Bagno LL, Carvalho D, Mesquita F, et al. Sustained IGF1 Secretion by Adipose-Derived Stem Cells Improves Infarcted Heart Function. Cell Transplant. 2016;25(9):16091622. doi: $10.3727 / 096368915 \times 690215$

9. Pluim BM, Zwinderman AH, van der Laarse A, van der Wall EE. The athlete's heart. A meta-analysis of cardiac structure and function. Circulation. 2000;101(3):336-344.

10. Kakilashvili B, Zurabashvili DZ, Turabelidze DG, Shanidze LA, Parulava GK. [The fatty acid composition of ordinary flax seed oil (Linum usitatissimum L.) cultivated in Georgia and its byological activity]. Georgian Med News. 2014(227):86-88

11. Kargar R, Forouzanfar M, Ghalamkari G, Nasr Esfahani
MH. Dietary flax seed oil and/or Vitamin E improve sperm parameters of cloned goats following freezingthawing. Cryobiology. 2017;74:110-114. doi:10.1016/j. cryobiol.2016.11.007

12. Ghanbari-Niaki A, Rahmati-Ahmadabad S. Effects of a fixed-intensity of endurance training and pistacia atlantica supplementation on ATP-binding cassette G4 expression. Chin Med. 2013;8(1):23. doi:10.1186/1749-8546-8-23

13. Rahmati-Ahmadabad S, Azarbayjani M, Nasehi $M$. The Effects of High-Intensity Interval Training with Supplementation of Flaxseed Oil on BDNF mRNA Expression and Pain Feeling in Male Rats. Annals of Applied Sport Science. 2017;5(4):1-12.

14. Shafiee A, kordi M, Gaeini A, Soleimani M, Nekouei A, Hadidi V. The Effect of Eight Week of High Intensity Interval Training on Expression of Mir-210 and EphrinA3 Mrna in Soleus Muscle Healthy Male Rats. Arak Med Univ J. 2014;17(3):26-34.

15. Hoydal MA, Wisloff U, Kemi OJ, Ellingsen O. Running speed and maximal oxygen uptake in rats and mice: practical implications for exercise training. Eur J Cardiovasc Prev Rehabil. 2007;14(6):753-760. doi:10.1097/ HJR.0b013e3281eacef1

16. Aoi W. Frontier impact of microRNAs in skeletal muscle research: a future perspective. Front Physiol. 2014;5:495. doi:10.3389/fphys.2014.00495

17. Sharma M, Juvvuna PK, Kukreti H, McFarlane C. Mega roles of microRNAs in regulation of skeletal muscle health and disease. Front Physiol. 2014;5:239. doi:10.3389/ fphys.2014.00239

18. Bo H, Jiang N, Ma G, et al. Regulation of mitochondrial uncoupling respiration during exercise in rat heart: role of reactive oxygen species (ROS) and uncoupling protein 2 . Free Radic Biol Med. 2008;44(7):1373-1381. doi:10.1016/j. freeradbiomed.2007.12.033

19. Hammond GL. Molecular and Cellular Endocrinology. Foreward. Mol Cell Endocrinol. 2010;316(1):1-2. doi:10.1016/j.mce.2009.09.015

20. Stokes KA, Nevill ME, Hall GM, Lakomy HK. Growth hormone responses to repeated maximal cycle ergometer exercise at different pedaling rates. J Appl Physiol (1985). 2002;92(2):602-608. doi:10.1152/jappl.2002.92.2.602

21. Rosendal L, Langberg H, Flyvbjerg A, Frystyk J, Orskov $\mathrm{H}$, Kjaer M. Physical capacity influences the response of insulin-like growth factor and its binding proteins to training. J Appl Physiol (1985). 2002;93(5):1669-1675. doi:10.1152/japplphysiol.00145.2002

22. Copeland JL, Heggie L. IGF-I and IGFBP-3 during continuous and interval exercise. Int J Sports Med. 2008;29(3):182-187. doi:10.1055/s-2007-965114

23. Turgut G, Kaptanoglu B, Turgut S, Genc O, Tekinturk S. Influence of acute exercise on urinary protein, creatinine, insulin-like growth factor-I (IGF-I) and IGF binding protein-3 concentrations in children. Tohoku J Exp Med. 2003;201(3):165-170.

24. Dall R, Lange KH, Kjaer M, et al. No evidence of insulinlike growth factor-binding protein 3 proteolysis during a maximal exercise test in elite athletes. J Clin Endocrinol Metab. 2001;86(2):669-674. doi:10.1210/jcem.86.2.7180

25. Manetta J, Brun JF, Maimoun L, Fedou C, Prefaut C, Mercier J. The effects of intensive training on insulin- 
like growth factor I (IGF-I) and IGF binding proteins 1 and 3 in competitive cyclists: relationships with glucose disposal. J Sports Sci. 2003;21(3):147-154. doi:10.1080/0264041031000070895

26. Ghanbari-Niaki A, Rahmati-Ahmadabad S, ZareKookandeh N. ABCG8 Gene Responses to 8 Weeks Treadmill Running With or Without Pistachia atlantica (Baneh) Extraction in Female Rats. Int J Endocrinol Metab. 2012;10(4):604-610. doi:10.5812/ijem.5305

27. Shirvani H, Ghanbari-Niaki A, Rahmati-Ahmadabad S, Sobhani V. Effects of endurance training and herb supplementation on tissue nesfatin-1/nucleobindin-2 and ghrelin mRNA expression. International Journal of Applied Exercise Physiology. 2017;6(1):71-84. doi:10.22631/ijaep. v6i1.118
28. Cave WT Jr. Dietary n-3 (omega-3) polyunsaturated fatty acid effects on animal tumorigenesis. FASEB J. 1991;5(8):2160-2166.

29. Zhang W, Thornton WH, MacDonald RS. Insulin-like growth factor-I and II receptor expression in rat colon mucosa are affected by dietary lipid intake. J Nutr. 1998;128(2):158-165. doi:10.1093/jn/128.2.158

30. Seti H, Leikin-Frenkel A, Werner H. Effects of omega-3 and omega- 6 fatty acids on IGF-I receptor signalling in colorectal cancer cells. Arch Physiol Biochem. 2009;115(3):127-136. doi:10.1080/13813450902905899

31. Katsuma S, Hatae N, Yano T, et al. Free fatty acids inhibit serum deprivation-induced apoptosis through GPR120 in a murine enteroendocrine cell line STC-1. J Biol Chem. 2005;280(20):19507-19515. doi:10.1074/jbc.M412385200 